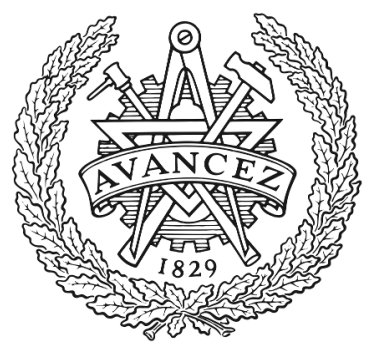

CHALMERS

UNIVERSITY OF TECHNOLOGY

\title{
LCA in architectural design-a parametric approach
}

Downloaded from: https://research.chalmers.se, 2023-04-25 23:42 UTC

Citation for the original published paper (version of record):

Hollberg, A., Ruth, J. (2016). LCA in architectural design - a parametric approach. International Journal of Life Cycle Assessment, 21(7): 943-960. http://dx.doi.org/10.1007/s11367-016-1065-1

N.B. When citing this work, cite the original published paper. 


\section{The International Journal of Life Cycle Assessment LCA in Architectural Design - A Parametric Approach --Manuscript Draft--}

\begin{tabular}{|c|c|}
\hline Manuscript Number: & JLCA-D-15-00116R2 \\
\hline Full Title: & LCA in Architectural Design - A Parametric Approach \\
\hline Article Type: & Original Paper \\
\hline Corresponding Author: & $\begin{array}{l}\text { Alexander Hollberg } \\
\text { Bauhaus University Weimar } \\
\text { Weimar, GERMANY }\end{array}$ \\
\hline \multicolumn{2}{|l|}{$\begin{array}{l}\text { Corresponding Author Secondary } \\
\text { Information: }\end{array}$} \\
\hline Corresponding Author's Institution: & Bauhaus University Weimar \\
\hline \multicolumn{2}{|l|}{$\begin{array}{l}\text { Corresponding Author's Secondary } \\
\text { Institution: }\end{array}$} \\
\hline First Author: & Alexander Hollberg \\
\hline \multicolumn{2}{|l|}{ First Author Secondary Information: } \\
\hline \multirow[t]{2}{*}{ Order of Authors: } & Alexander Hollberg \\
\hline & Jürgen Ruth, Prof. Dr.-Ing. \\
\hline \multicolumn{2}{|c|}{ Order of Authors Secondary Information: } \\
\hline \multicolumn{2}{|l|}{ Funding Information: } \\
\hline Abstract: & 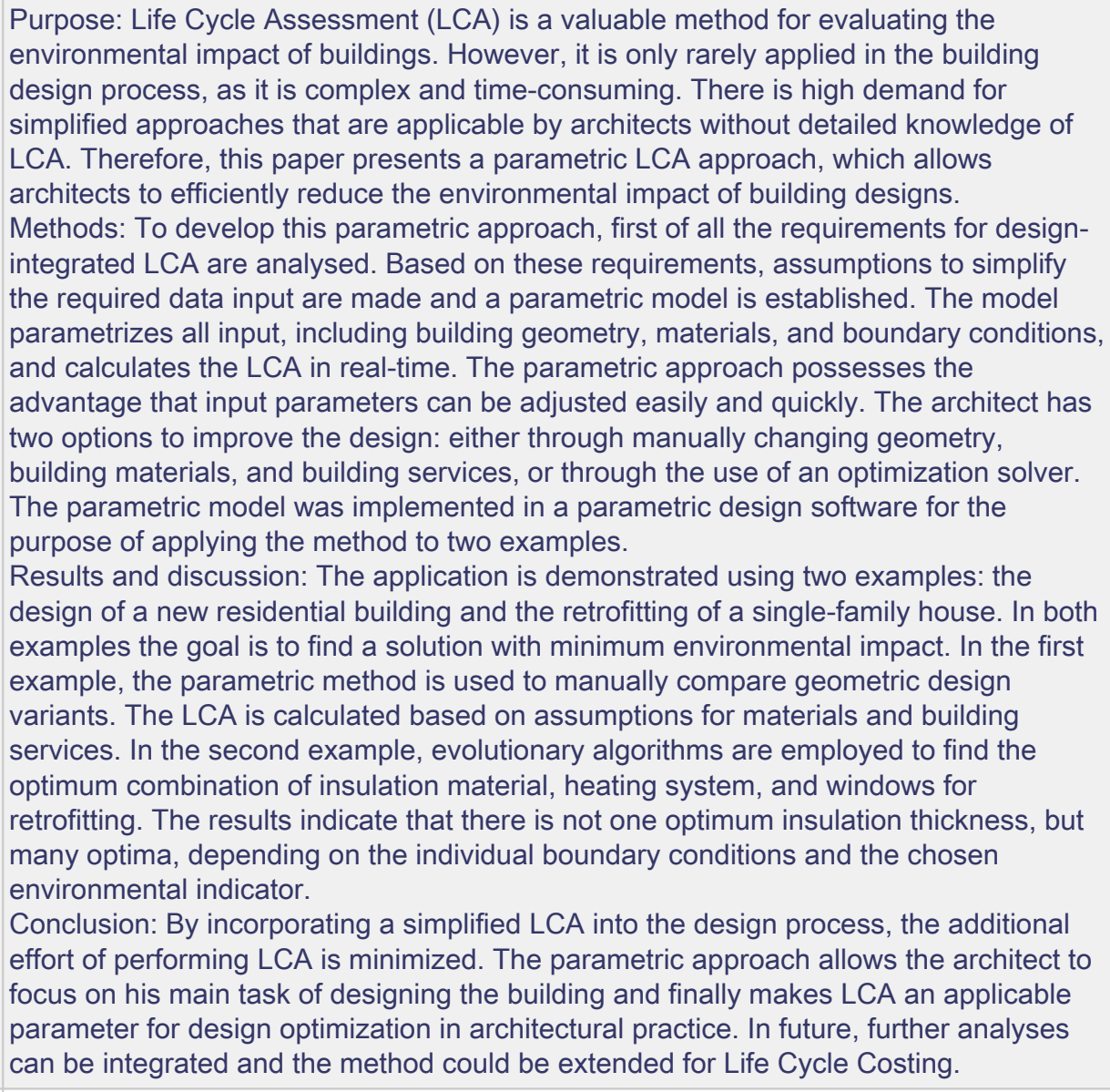 \\
\hline Response to Reviewers: & $\begin{array}{l}\text { Dear reviewers, thank you very much for your comments. I responded to them in the } \\
\text { attached file. }\end{array}$ \\
\hline
\end{tabular}




\title{
LCA in Architectural Design - A Parametric Approach
}

\author{
Authors: \\ Alexander Hollberg \\ Bauhaus University Weimar \\ Chair of Structural Design \\ Belvederer Allee 1 \\ 99425 Weimar \\ +493643583162 \\ alexander.hollberg@uni-weimar.de \\ Prof. Dr.-Ing. Jürgen Ruth \\ Bauhaus University Weimar \\ Chair of Structural Design
}


Abstract

Purpose: Life Cycle Assessment (LCA) is a valuable method for evaluating the environmental impact of buildings. However, it is only rarely applied in the building design process, as it is complex and time-consuming. There is high demand for simplified approaches that are applicable by architects without detailed knowledge of LCA. Therefore, this paper presents a parametric LCA approach, which allows architects to efficiently reduce the environmental impact of building designs.

Methods: To develop this parametric approach, first of all the requirements for design-integrated LCA are analysed. Based on these requirements, assumptions to simplify the required data input are made and a parametric model is established. The model parametrizes all input, including building geometry, materials, and boundary conditions, and calculates the LCA in real-time. The parametric approach possesses the advantage that input parameters can be adjusted easily and quickly. The architect has two options to improve the design: either through manually changing geometry, building materials, and building services, or through the use of an optimization solver. The parametric model was implemented in a parametric design software for the purpose of applying the method to two examples.

Results and discussion: The application is demonstrated using two examples: the design of a new residential building and the retrofitting of a single-family house. In both examples the goal is to find a solution with minimum environmental impact. In the first example, the parametric method is used to manually compare geometric design variants. The LCA is calculated based on assumptions for materials and building services. In the second example, evolutionary algorithms are employed to find the optimum combination of insulation material, heating system, and windows for retrofitting. The results indicate that there is not one optimum insulation thickness, but many optima, depending on the individual boundary conditions and the chosen environmental indicator.

Conclusion: By incorporating a simplified LCA into the design process, the additional effort of performing LCA is minimized. The parametric approach allows the architect to focus on his main task of designing the building and finally makes LCA an applicable parameter for design optimization in architectural practice. In future, further analyses can be integrated and the method could be extended for Life Cycle Costing.

Keywords: sustainable building, parametric design, architectural design process, optimization, simplified LCA 
Nomenclature

Name

Unit I

$E D$

M

$R$

RSP

$R S L$

IF

PF

PET

PERT

PENRT

GWP

EP

AP

$O D P$

POCP

ADPE

Subscript:

\begin{tabular}{ll}
$L C$ & Life Cycle \\
\hline & Operational \\
$E$ & Embodied \\
heat & Heating \\
env & Building envelope \\
pri & Primary structure
\end{tabular}

kWh

$\mathrm{kg}$

Number of replacements

Reference service period (of the building)

a

a

MJ

MJ

MJ

$\mathrm{kg} \mathrm{CO}$-eqv.

kg R11-eqv.

$\mathrm{kg} \mathrm{SO}_{2}$-eqv.

$\mathrm{kg} \mathrm{PO}_{4}{ }^{3-}$-eqv.

$\mathrm{kg} \mathrm{C}_{2} \mathrm{H}_{4}$-eqv.

kg Sb-eqv. 


\section{Introduction: Sustainable Building and Life Cycle Assessment}

1.1. The global problem and existing measures

The building sector is responsible for a large proportion of the world's consumption of energy and resources and has a significant environmental impact. About 50\% of the world's processed raw materials are used for construction (Hegger et al. 2007). Buildings account for more than $40 \%$ of the world's primary energy demand and one third of greenhouse gas emissions (UNEP SBCI 2009).

The general public became aware of the great amount of energy consumed for the operation of buildings in the 1970s, triggered by the first oil crisis and the resulting rise in costs for fossil energy carriers. Most governments of industrialized countries reacted by introducing regulations on the energy demand of buildings, such as the first German Thermal Insulation Ordinance, in 1977. Over the years the requirements have been made steadily more demanding, and contemporary regulations, such as the German Energy Saving Ordinance (EnEV 2013), are very strict. In addition, governments have introduced financial incentives for exceeding the requirements of the current regulation. For example, the German government-owned development bank (KfW) awards subsidies for new buildings and retrofitting measures if the requirements of the EnEV 2014 are exceeded.

Whether enforced by law or motivated by incentives, current planning approaches attempt to reduce the energy demand for the operation of buildings as much as possible. State-of-the-art measures employ, among other things, very high insulation thicknesses, highly insulated thermal windows, and mechanical ventilation. All of these measures require resources and energy, both for their initial production and again for their later disposal. The question is therefore whether the energy and environmental savings achieved through these measures are greater than the consumption of energy and resources for their production. This can be answered using Life Cycle Assessment (LCA).

\subsection{The need for LCA in the building sector}

The energy demand of buildings over the entire life cycle can be divided in two types: the operational energy demand in the use phase, and the energy embodied in the production, construction, and replacement of components, as well as their disposal at the end of their useful life. The measures implemented to reduce operational energy demand have caused the ratio of operational energy to embodied energy to shift in recent years. Figure 1 shows the distribution of primary energy demand for residential buildings under different historical energy standards in Germany over a reference service period of 50 years. Before the first Energy Saving Ordinance (EnEV) was introduced in 2002, operational energy demand accounted for a share of more than $85 \%$ of the life cycle primary energy demand. Embodied energy was thus insignificant and could be neglected. With the tightening of building regulations, the overall life cycle energy demand has been reduced, but the share of embodied energy has risen for two reasons: first, operational energy demand has been successfully reduced, causing the relative contribution of embodied energy to rise. Second, the measures themselves increase the embodied energy, increasing the absolute embodied energy.

The embodied energy of a residential building in Passivhaus standard accounts for a share of more than 30\% (El Khouli et al. 2014) of the whole life cycle primary energy demand. According to Passer et al. (2012), energy optimization measures for the use phase in low-energy buildings, such as the Passivhaus standard, have reached the limit of what can be achieved. Nevertheless, the Energy Performance Directive of the European Union 2010/31/EU stipulates a further reduction of operational energy demand. Beginning in 2021, only Nearly-Zero 
Energy Buildings (NZEBs) will be allowed to be built (EU 2010). NZEBs are defined as buildings that produce legal definition is still lacking (Weißenberger et al. 2014). As the operational energy demand of NZEBs will be close to zero, the proportional contribution of embodied energy will be nearly $100 \%$. The only way to further reduce the life cycle primary energy demand of NZEBs will be to minimize the embodied energy. This clearly shows the need for LCA in the design of buildings. Until now, however, European regulations have only existed for operational energy, while embodied energy is still neglected (Szalay \& Zöld 2007).

\subsection{Challenges of LCA in the architectural design process}

LCA of buildings is currently a complex and very time-consuming procedure (Wittstock et al. 2009;

Weißenberger et al. 2014; Zabalza Bribián et al. 2009). There are various reasons for this: first of all, buildings usually consist of different building components, each consisting of many different materials, which makes the necessary assessment of all material quantities a laborious task. Secondly, many buildings possess a very long life span with a use phase that can easily last hundreds of years. Additionally, a building's use may change over time, introducing a high degree of uncertainty. Besides the use phase, the end-of-life scenario is also very uncertain. Most consumer products are produced by a single manufacturer, who can take back the product and recycle it or dispose of it in a controlled way, as its constituent parts are known. In buildings, however, products made by different manufacturers are often inseparably connected. A further challenge is the lack of environmental data for building materials. Data availability has been improved within the last couple of years (Passer et al. 2015) and for the proposed method within this paper, it is assumed that an adequate, local database will be available when applying the method.

Additional challenges arise when applying LCA during the architectural design process. In general, architects lack the knowledge and experience necessary to carry out an LCA. Therefore, simplified approaches to conducting an LCA are needed which incorporate the knowledge of LCA experts in a design tool and allow the architect to focus on the main task of designing the building. The nature of the architectural design process makes the application of LCA difficult. The design process usually consists of several phases, which are defined similarly in most industrialized countries. In this case, the process was divided into six stages, similar to El Khouli et al. (2014), as shown in Figure 2.

The design process begins with preparation in stage one, which consists of preliminary studies, research, feasibility studies and the definition of project roles. If an architecture competition is held, this work is usually carried out by the competition initiators and the information is provided to the participants.

In the second stage a basic architectural concept is developed. This is where the most fundamental decisions are made, including the number of storeys, building orientation, and the massing of the building. Decisions made in these early stages have the greatest influence (Hegger et al. 2007), because they define key parameters for the remainder of the design process. Here, LCA would be a valuable tool to evaluate the environmental impact of design proposals (Fuchs et al. 2013).

In the third stage the design is refined and the final geometry is determined. The material of the primary construction and building envelope is defined in a generic way. While the general choice of material is known, e.g. concrete, its precise quality characteristics and manufacturer are not yet decided. The building permit application usually follows this phase. In Germany, a permit application should theoretically include a 
calculation of the operational demand. In practice, the calculation is often only carried out shortly before construction commences.

In the fourth stage, design details are drawn up and technical specifications are defined. Tendering and procurement is carried out at the end of this phase. If available, specific Environmental Product Declarations (EPDs) can be employed for LCA. Only at this point is all of the information available to proceed with the LCA.

Stage 5 is the construction of the building, culminating in the handover of the building to the client. To a certain degree, the way the building is used also influences energy consumption, e.g. the temperature that the tenants desire in their rooms (Hegger et al. 2007). However, a large part of the operational demand has already been defined in the design process, for example by the thermal quality of the building envelope, the window and floorplan layout, and the choice of heating and ventilation systems.

The dilemma of LCA during the design process is that decisions taken in stage 2 have the greatest influence, but the information available is scarce and uncertain. The exact bill of quantities (BoQ) and product-specific information needed for a complete LCA are only available after stage 4 , but by then the results are less useful because it is too costly to make changes at this stage. It may be possible to exchange a few materials, but changes to the building's geometry, which could significantly reduce the environmental impact, are close to impossible. Basically, once the necessary information is available, the LCA results are impractical to implement. Even if the required information is available beforehand, it is not sufficiently integrated into the architectural design (Hildebrand 2014). Bates et al. (2013) see the key limitation in "the translation between the distant language of LCA and the grammar of building construction". In the few cases that LCA is conducted in practice, it is needed for a sustainable building certification. Usually, the building is only evaluated after the tendering procedure in stage 4 , which is late in the design process. Baitz et al. (2012) describe the general discrepancy between the application of LCA in theory and practice and show that there is demand for simplified, timeefficient LCA approaches.

In addition, evaluating the building design through LCA is not sufficient on its own, as it does nothing to improve the design. In order to minimize environmental impact, an optimization based on different design variants is needed. As most buildings are unique designs, the parameters that influence their energy performance vary from building to building. This makes every kind of optimization difficult when compared with a serially produced product. For consumer products, a lot of time can be invested in finding the optimal solution, because even a very small improvement in the individual product has a great impact when multiplied by the vast number of products sold. The uniqueness of building designs means that a very time-efficient way of finding a solution that lies close to the optimum is needed. Deadlines in the design process are short, and in the words of Baitz et al. (2012): "You can NOT reduce $\mathrm{CO}_{2}$ with a 'good' and scientifically brilliant LCA, if it is NOT applied."

\subsection{Computer-aided approaches in practice}

Various computer-aided approaches exist to facilitate the LCA of buildings. Reviews and comparison of LCA tools can be found in the literature, e.g. Zabalza Bribián et al. (2009), Lasvaux et al. (2012), El Khouli et al. (2014). For this paper, LCA tools for buildings have been classified in four categories:

\section{Generic LCA tools}


Typical generic LCA tools, such as Gabi, SimaPro or OpenLCA have been developed for the LCA of products or processes. Wittstock et al. (2009) conducted an LCA of a building using a generic model of such software. The input of areas occurs in tabular form. From an architect's point of view, these tools are not practical, because they do not mesh with the design process. Furthermore, they require extensive background knowledge.

\section{Spreadsheet-based calculation}

Most tools are based on a spreadsheet, and the user has to manually input the BoQ. The embodied impact is calculated by multiplying the material quantities by mass with environmental data on the respective materials, which can be found in databases or EPDs. Some tools integrate the operational environmental impact, but the user has to input the externally calculated energy demand manually. Exceptions to this are Legep and Elodie, which can internally calculate the operational energy demand. The manual input of the geometry in tabular form is time-consuming and error-prone: surfaces, for example, can easily be missed and escape notice. Furthermore, the effort for the manual input means that users are unwilling to investigate more variants than absolutely necessary, and as such do not exploit the optimization potential.

\section{Building component catalogues}

In various countries, online catalogues are available that facilitate the LCA of building components, e.g. the Swiss Bauteilkatalog and the German eLCA. Online access has the advantage that environmental data can be updated continuously in the background. The catalogues are based on a tabular input of the quantities from which a BoQ is extracted and multiplied with the respective environmental data. Typical components are predefined and can be adapted quickly. In some cases, the externally calculated operational demand can be integrated. If the operational energy demand is calculated externally, it is not linked to the thermal quality of the building envelope. A change in the material of the envelope, for example switching the insulation to another material with a different conductivity, causes a change in heating demand, which means a new external calculation has to be undertaken and the results have to be input again. This high labour intensity prevents users from calculating variants for an optimization process.

\section{CAD integrated tools}

Recently, LCA tools that are integrated into 3D computer-aided design (CAD) programs have become available, e.g. Impact and Tally. The BoQ is generated automatically from the geometric model and multiplied with the environmental data. These geometry models are called Building Information Models (BIM). In theory, LCA is easily conducted with BIM. In practice, the challenge lies in the high complexity that BIM can achieve. As a consequence, a means of managing BIM is required for large projects, while for small projects it is usually not employed at all. Additionally, this complexity reduces the likelihood of modelling various design proposals to optimize based on variant comparison. Therefore, the application of BIM in the crucial early design stages is not practicable.

Table 1 gives an overview of currently available computer LCA tools. While all tools are designed to calculate the embodied environmental impact, none of them covers all features needed for application during early design stages, namely: a link to a 3D model for the geometry input, the ability to calculate the operational energy demand, and the possibility for optimization. This illustrates the lack of an adequate tool for design-integrated LCA. 


\subsection{Computer-aided approaches in research}

Literature on new approaches to integrate LCA in the architectural design process mainly focusses on BIM. The basic concept behind the combination of BIM and LCA is described in Neuberg (2004) and Ekkerlein (2004). Seo et al. (2007) demonstrate their BIM-based LCA approach for the detailed design stage of a commercial building in Australia. Antón \& Díaz (2014) perform a SWOT analysis for the Integration of BIM and LCA in the early design stages and show the demand for design-integrated approaches. Basbagill et al. (2013) provide a literature review of BIM-integrated LCA. Furthermore, they present their own approach to combining various software packages: the BIM software DProfiler, eQuest for energy simulation, SimaPro and Athena EcoCalculator for LCA. Similar approaches combining multiple software packages can be found in other studies, e.g. Aurélio et al. (2011), who use TRNSYS, SketchUp, and OpenLCA. These setups deliver detailed results, but expert knowledge is needed to operate such complex software combinations.

Flager et al. (2011) also employ BIM and a combination of analysis software for optimization based on LCA. Based on a cradle-to-gate analysis, they optimize the building envelope towards minimum life cycle costs (LCC) and minimum Global Warming Potential. Ostermeyer et al. (2013) also optimize towards minimum LCA and LCC results and provide a Pareto front for one case study. Again, a chain of analysis software is employed which is far too complex for application in practice.

Next to BIM, parametric design has become a major trend in CAD in recent years. Parametric design has been known for a long time, but only the recent availability of suitable computer tools has promoted its wider application in architecture and design (Davis 2013). In standard CAD-software, geometric forms are drawn the same way the architect would draw on paper: once drawn, the geometry is fixed and changes in the design require redrawing the initial geometry. The parametric approach describes the geometry using mathematical formulae. The form is then based on defining parameters, such as the width, height, and length of a cube. These parameters can easily be changed afterwards, making it possible to quickly vary the basic form. Furthermore, this permits the automated generation of variants by computers, and this can serve as the basis for an optimization process. A number of parametric tools exist for building performance analysis, e.g. Honeybee (Roudsari et al. 2013), Diva (Jakubiec \& Reinhart 2011), or TRNSYS-Lizard (Frenzel \& Hiller 2014). Furthermore, Nembrini et al. (2014) describe the advantages of parametric scripting for energy performance optimization, but this approach requires expert knowledge in scripting.

Parametric approaches for building LCA are rare. Heeren et al. (2015) describe a detailed parametric model for joint assessment of operational and embodied environmental impact. A great number of parameters can be varied and the geometry is integrated as one parameter, but a link to CAD is missing. Therefore, the approach is valuable for research purposes, but impractical for design practice.

\section{Methods: Parametric LCA}

2.1. Requirements for design-integrated LCA

The following requirements can be derived from the challenges of incorporating LCA into the architectural design process and the remaining issues of current approaches: 
To allow architects and planners to assess their design ideas during the design process, a method is needed that is both easy to understand and applicable without extensive knowledge and experience in LCA. The process must be simplified and its focus restricted to the most relevant aspects in the complex and often uncertain life cycle of buildings.

The method should be applicable in the early design stages, where its relevance is greatest. Since detailed information is usually not available at this stage, the method must be able to proceed with missing information and make adequate assumptions to fill in the gaps. In a traditional design process (see Figure 3 a), the architect develops a number of geometric variants and then decides on one geometry. In the next step the architect provides a number of material variants and chooses one material. The decisions are based on educated guesses, because the LCA can only be carried out at the end of the process, when all parameters, including building services, etc. have been determined. Using assumptions for the following steps, the method should be able to carry out the LCA during the first step to provide a quantitative basis for deciding on a geometry. The result is a decision tree (see Figure $3 \mathrm{~b}$ ).

In order to replace these assumptions with specific data as it becomes available, the method should employ models, which can be continuously adapted and refined. The EeBGuide (Wittstock et al. 2012) distinguishes between three categories of building LCA: screening LCA, simplified LCA, and complete LCA. To facilitate the workflow, a consistent model is needed, which can be applied for screening purposes and be extended until it reaches the level of detail required for a complete LCA.

The results should be presented in a way that is understandable for users that do not have detailed knowledge of LCA. In general, the absolute results are not meaningful to non-experts: for example, a client is probably unable to interpret the statement "your building design has an acidification potential of $0.3 \mathrm{~kg} \mathrm{SO}$-equivalent $/ \mathrm{m}^{2} \mathrm{a}$ ". A more promising approach in this respect is to use the results of the LCA to compare different design variants. It is far easier to communicate that design A possesses $3.7 \mathrm{t} \mathrm{CO}_{2}$-equivalent less global warming potential than designs $\mathrm{B}$ and $\mathrm{C}$ with the same function. The client can then make an informed decision taking other parameters into consideration, such as costs.

\subsection{Data sources and system boundaries}

For LCA of buildings, two kinds of system boundaries have to be defined. Next to the system boundaries on the product/material level - the border between technosphere and biosphere - the system boundaries at the building level need to be determined. Therefore, the European standard for LCA of buildings, DIN EN 15978 (2012), divides the life cycle of buildings into four stages, with an additional stage for benefits beyond the system boundaries (see Figure 4).

In order to conduct LCA of buildings, different kinds of data on materials are needed. All data is combined in one spreadsheet-based databank (see Table 3). The data is divided into three categories: physical, environmental, and RSL. If the LCA is to be combined with other analyses, such as daylight, statics, or LCC analyses, additional data can easily be added to the databank.

\subsubsection{Physical properties}

The physical properties include the density needed to convert between volume and mass. Further properties, such as conductivity or heat capacity are needed to calculate the operational energy demand with thermal simulation. 


\subsubsection{Environmental data}

In contrast to the LCA of products, which follows the four phases of ISO 14040, the life cycle inventory (LCI) and life cycle impact assessment (LCIA) are usually merged into one phase for building LCA, because predefined LCI data or EPDs are employed (Lasvaux \& Gantner 2013). This data has already been aggregated into several environmental indicators. In this paper, this aggregated data is called "environmental data".

Only certain life cycle modules are considered within this paper (see Figure 4). First of all, the product stage (A1-A3) is considered. According to Kellenberger \& Althaus (2009), the transportation to the construction site (A4) can become relevant in some cases. However, here we are concerned with a simplified method for early design stages where the architect is unlikely to know the production location, which makes the calculation of transportation distances difficult. Environmental data on the construction process (A5) is also rare. Modules A4 and A5 were thus neglected. Similarly, the building's end of life, including its demolition (C1) and the transportation of waste (C2) are neglected, but waste processing (C3) and disposal (C4) are considered. These modules and the replacement of products/components within the use of the building (B4) form the embodied impact. Module D can be optionally integrated.

Only the operational energy demand (B6) is integrated into the use stage. According to Wittstock et al. (2012), the operational water use should also be assessed. However, the design of the building has little influence on water use and it has thus been neglected.

Based on DIN EN 15978 (2012), the following indicators are integrated:

- PET Total primary energy

- PERT Total renewable primary energy

- $\quad$ PENRT Total non-renewable primary energy

- GWP Global Warming Potential for a time horizon of 100 years

- EP Eutrophication Potential

- AP Acidification Potential

- ODP Ozone Layer Depletion Potential

- POCP Photochemical Ozone Creation Potential

- ADPE Abiotic Resource Depletion Potential for elements

Data from the German ökobau.dat (BMUB 2015) and EPDs which comply with EN 15804 was employed. Some datasets in the ökobau.dat only provide cradle-to-gate (A1-A3) data and the adequate end-of-life process (C3, C4 and D) has to be chosen by the user. For this paper, the choice was based on the eLCA tool (BBSR 2014).

\subsubsection{Reference service life}

We used RSL data employed for German building certification DGNB (DGNB 2015) and BNB (BBSR 2015) which is provided by the German Federal Institute for Research on Building, Urban Affairs, and Spatial Development (BBSR 2013).

\subsection{Parametric Model}

The key element of the proposed method is a digital parametric model. The geometry, materials, building services, and boundary conditions are defined parametrically, permitting quick adaptability and variation. The workflow is shown in Figure 5. 


\subsubsection{Input}

First of all, the geometry is input. The geometric model consists exclusively of 2D surfaces of the main building components. The materials and layer thickness of each component are input in the material editor. Next to the materials, the type of building services are chosen. Further boundary conditions, such as climate data, user profiles, and the reference service period (RSP) have to be defined. The RSP is also input parametrically, making it possible to quickly compare an RSP of 50 years to 100 years, for example, or to adapt the assessment for a specific building certification system.

\subsubsection{Calculation}

The presented approach combines the primary energy demand and environmental impact of the building in the term 'impact'. It distinguishes between the operational impact $\left(\mathrm{I}_{\mathrm{O}}\right)$ and the embodied impact $\left(\mathrm{I}_{\mathrm{E}}\right)$. The life cycle impact $\left(\mathrm{I}_{\mathrm{LC}}\right)$ is the sum of $\mathrm{I}_{\mathrm{E}}$ and $\mathrm{I}_{\mathrm{O}}$ (see Eq. 1). While this is a general formula, only the life cycle modules indicated in Figure 4 are integrated in the calculation in this paper.

$$
I_{L C}=I_{O}+I_{E}
$$

$\mathrm{I}_{\mathrm{O}}$ consists of the sum of all different kinds of energy demand during the use phase $\left(\mathrm{ED}_{\mathrm{i}}\right)$ divided by the performance factor $\left(\mathrm{PF}_{\mathrm{i}}\right)$ for the specific building service and multiplied by the impact factor of the energy carrier $\left(\mathrm{IF}_{\mathrm{O}, \mathrm{i}}\right)$ (see Eq. 2). In general, there are two possibilities for determining ED: dynamic building simulation, such as EnergyPlus (DOE 2015) or TRNSYS (TRNSYS 2015) or a quasi-steady state method, such as DIN V 18599 (2011). Both can be equally employed here. ED is usually calculated with reference to one year of operation. Therefore, the sum is multiplied by the number of years of the RSP. The PF is introduced to describe different types of building services with one systematic method. It equals the annual performance factor for a heat pump or the efficiency for a gas-condensing boiler. The operational impact factor (IF $)_{0}$ is imported from the combined databank and depends on the energy carrier employed and the indicators chosen for the LCA.

$$
I_{O}=\sum_{i}\left(E D_{i} / P F_{i} \times I F_{O, i}\right) \times R S P
$$

The embodied impact is usually calculated by multiplying the BoQ with the respective LCI data. In the presented approach, the mass of each material $\left(\mathrm{M}_{\mathrm{j}}\right)$ is multiplied by the specific impact factor of the material $\left(\mathrm{IF}_{\mathrm{E}, \mathrm{j}}\right)$. To determine the mass, first of all, the areas of the different building surfaces have to be calculated. The surface areas are then multiplied with the thickness and density of the specific material. The density is imported from the combined databank, together with the RSL and the specific environmental data. If the RSL of a building component is lower than the RSP of the building, the necessary number of replacements $\left(\mathrm{R}_{\mathrm{j}}\right)$ is added. In this way, the $\mathrm{I}_{\mathrm{E}}$ of every component is calculated and added up to obtain the $\mathrm{I}_{\mathrm{E}}$ of the complete building (see Eq. 3).

$$
I_{E}=\sum_{j}\left(M_{j} \times I F_{E, j} \times\left(1+R_{j}\right)\right)
$$

The impact factors $\left(\mathrm{IF}_{\mathrm{O}, \mathrm{i}}, \mathrm{IF}_{\mathrm{E}, \mathrm{j}}\right)$ depend on the indicator chosen for the LCA. If more than one indicator is used for the LCA, the impact factors are written as vectors of the indicators applied (see Eq. 4). In consequence, the resulting impact $\left(\mathrm{I}_{\mathrm{O}}, \mathrm{I}_{\mathrm{E}}\right)$ is a vector, too. In this way, the impact factors can easily be adapted depending on the available data or the scope of the LCA. 
All terms of the equations are assumed to be static, although some values might change in future, such as the PF of the building services. Furthermore, the electricity mix will change and as result the environmental data of the material will also change. Replaced building components will then have a lower embodied impact. All of these considerations could be integrated into the equations in the future, leading to a dynamic LCA, for example as described by Collinge et al. (2013).

To simplify the procedure, especially in the early design stages, only the most relevant aspects of both parts should be considered. In later stages of the design process more aspects can easily be added, continuously extending the model from a screening type towards a complete LCA. The relevance of specific aspects depends on the building type and boundary conditions, such as climate: different aspects are relevant for a single-family house in Norway than they are for an office building in Dubai. The simplification is explained in detail in section 3.2 .

\subsubsection{Output}

The aim is to provide the architect with insight into the environmental impact of the design, and to indicate potential for improvement. In addition to the final LCA results, partial results, e.g. the operational impact of heating, or the embodied impact of windows can be output. A graphic representation is shown in Hollberg et al. (2016). The results are reported according to the indicators defined by the impact factors. Normalizing, weighting, and aggregating of several indicators into a single score is also possible. The parametric approach allows the users to define and adapt their own weighting factors. In this paper, weighting has not been applied, because no scientific method exists according to ISO 14040.

\subsubsection{Optimization}

There are two approaches to improve a design's environmental impact. In the first approach, the architect manually generates different variants and then compares the results to find those that indicate better environmental performance. The architect can then successively optimize the design in an iterative process. The architect can influence the environmental impact using two fundamental parameters: geometry and materials/building services. Usually, the design process starts with the definition of building volumes according to functional requirements and restrictions dictated by the urban context or building regulations, such as maximum amount of storeys. Step by step, the building volume is defined in more detail along with the general window layout. In most cases, this is done in stage 2, while the material is defined in stage 3 or 4 . The parametric model uses default materials in order to calculate the LCA before the choice of material has been finalized. The aim is to evaluate and compare different geometries of the building and their environmental impact in stage 2 . Sometimes the material has been chosen prior to the design phase, for example, if the client 
specifies timber construction. In this case, the architect can choose this material and then start to vary and improve the design.

The second approach employs algorithms that automatically generate variants. A series of alterable parameters for example determining the geometry or the material, the window layout or the material of the window frame is assigned to the optimizer, which has the objective function of minimizing $\mathrm{I}_{\mathrm{LC}}$. The design is then optimized in an iterative process, beginning with the assessment of the environmental impact of the initial design. The optimizer then tries to lower the impact by varying the parameters until an abort criterion is fulfilled, typically a certain runtime or number of solutions. It is assumed that the optimum has then been found and the solution is output.

Both approaches have their advantages and disadvantages. The optimizer can generate and evaluate a lot of variants in a short space of time and probably find a better solution than the architect's own experiments with manually generated variants (Szalay et al. 2014). But if the architect is not familiar with the algorithm that drives the optimization process, it may appear to be a 'black box'. Furthermore, the automatically derived solution may not appeal to the architect for other reasons, such as aesthetic appearance. Manually changing the design allows the architect to consider additional aspects and boundary conditions.

\subsection{Parametric LCA tool}

We implemented the parametric LCA model in Grasshopper3D (Rutten 2015), a parametric design software based on the 3D CAD Software Rhinoceros (Robert McNeel \& Associates 2015). The geometry can either be built directly in Grasshopper3D or drawn in Rhinoceros and then transferred automatically to Grasshopper3D. The material and thickness is defined in the material editor in Grasshopper3D. The combined database (as shown in Table 3) is imported. For the calculation of energy demand, a quasi-steady state method based on DIN V 18599 (2011) was employed, which was developed by Lichtenheld et al. (2015). The calculation of both operational energy demand and embodied impact are fully integrated into Grasshopper, making exporting and reimporting unnecessary. In this way, the parametric tool is able to calculate the LCA in real time. The results are displayed in the Rhinoceros viewport and simultaneously exported to a spreadsheet.

\section{Results: Examples of application}

Two examples demonstrate the application of the parametric LCA model. The first employs the model to evaluate the environmental impact of different manually generated design proposals in the conceptual design stage of a multi-family house. The second describes the application of computational optimizers for investigating the optimum insulation in the detailed design stage of a single-family house retrofit.

\subsection{Assumptions}

To simplify the process and only consider the most relevant aspects, the following assumptions for operational and embodied impact assessment were made:

Lützkendorf et al. (2015) distinguish between building-related operations, such as space heating and cooling, and user-related operations, such as appliances. The architect can influence the building-related operations and thus this aspect was considered. On the other hand, user-related operations were neglected, as the architect has little influence over them through the design. 
Within building-related operations, only space heating was considered. According to DENA et al. (2012), the energy needed for space heating amounts to 75 - $85 \%$ of total operational energy demand (see Figure 6). For commercial and office buildings, the energy demand for lighting and cooling can also be relevant, especially in other climate zones. However, for the purposes of analysing the residential buildings in the following examples, they have been omitted.

For the simplified calculation of $\mathrm{I}_{\mathrm{E}}$, only the building envelope and primary load-bearing construction are assessed. According to El Khouli et al. (2014), these account for about $75 \%$ of the embodied primary energy (see Figure 7). The interior outfitting is very dependent on the occupant and is often replaced before the end of its lifetime. This introduces a high level of uncertainty into the assumptions for the reference service lives of the interior building components. In residential buildings, the embodied energy for building services currently still plays a minor role and is therefore also omitted. This situation is likely to be different for office buildings and will in general become more significant in future as building services, monitoring, or building automation components become more common installations in domestic buildings. Next to the simplifications above, only the life cycle modules indicated in Figure 4 are considered here. If in future data on the neglected modules are available they can easily be integrated in a similar manner.

With these simplifications, the $\mathrm{I}_{\mathrm{E}}$ equals the sum of embodied impact for the building envelope ( $\mathrm{I}_{\mathrm{E}, \text { env }}$ ) and primary construction $\left(\mathrm{I}_{\mathrm{E}, \mathrm{pri}}\right)$. The whole $\mathrm{I}_{\mathrm{LC}}$ can then be written in one simple formula:

$$
\begin{aligned}
& I_{L C}=E D_{\text {heat }} / P F_{\text {heat }} \times I F_{O, \text { heat }} \times R S P+ \\
& \sum_{e n v}\left(M_{\text {env }} \times I F_{E, \text { env }} \times\left(1+R_{\text {env }}\right)\right)+\sum_{\text {pri }}\left(M_{\text {pri }} \times I F_{E, p r i} \times\left(1+R_{\text {pri }}\right)\right)
\end{aligned}
$$

\subsection{Examples}

\subsubsection{Massing study for new residential building}

This example demonstrates the application of the developed method for a notional conceptual design of a multifamily house. The aim is to provide a decision tree as shown in Figure $3 b$ to evaluate four different hypothetical geometric variants in the conceptual design stage.

The notional building should provide six apartments with a gross floor area (GFA) of $150 \mathrm{~m}^{2}$ each. The building is located in a suburban context, without shading from neighbouring buildings, in Potsdam, Germany. The storey height is $3 \mathrm{~m}$, and there is no basement. The window area is 1/8 of the GFA of each storey, which is the minimum requirement according to German state building regulations, cf. (BauO Bln 2011). DIN V 18599 is employed for the energy demand calculation, and it is assumed that the ventilation occurs naturally. The RSP is 50 years.

For each of the geometric variants, a combination of the energy standard for the building envelope, the construction material of the envelope and primary structure, and the heating systems was assumed. Two example energy standards for the building envelope are chosen: one fulfils the minimum U-values of the German Energy Saving Ordinance (Bundesregierung 2013) and one corresponds to the minimum U-values for the Passivhaus standard (McLeod et al. 2015). Three material variants for the building envelope and primary structure are compared (see Table 2). Two heating systems, a gas-condensing boiler with a PF of 0.98 and a heat pump 
fuelled by electricity from the German energy mix with a PF of 4.8, are employed. The environmental, physical, and RSL data employed is shown in Table 3.

To demonstrate the method, only one environmental indicator (PENRT) is chosen, but the approach works similarly for all indicators. Combining all parameters results in 12 possible solutions for each geometry. The result for each solution in MJ/a is shown in the last column 'Heating system' of the decision tree in Figure 8. The column 'Material' shows the average of both solutions which can be achieved with this choice of material. Likewise, the column 'U-value' shows the average of solutions of the following steps. Finally, the column 'Geometry' shows the average of possible solutions for the four geometric variants.

\subsubsection{Retrofitting of a single-family house}

The second example demonstrates the application of the developed method for retrofitting a residential building using computational optimizers. The reference building is a typical single-family house in Potsdam, Germany from the 1960s, and the building task is to retrofit the thermal envelope of the building with insulation. The objective is to determine the optimum insulation material and optimum insulation thickness, taking into consideration the heating system, the energy carrier, and the location. Furthermore, an investigation as to whether the original windows should be exchanged will be undertaken.

The objective of the optimization is to find the trade-off between $\mathrm{I}_{\mathrm{O}}$ and $\mathrm{I}_{\mathrm{E}}$. Increasing the insulation thickness causes a reduction in $\mathrm{I}_{\mathrm{O}}$ and a rise in $\mathrm{I}_{\mathrm{E}}$. With increasing thickness, the $\mathrm{U}$-value of the building envelope converges asymptotically towards zero. Thus, each additional centimetre of insulation contributes less to reducing transmission heat loss than the previous one. Consequently, there is an 'environmental break-even point'. It is then no longer worthwhile to add further insulation because the added $\mathrm{I}_{\mathrm{E}}$ cannot be amortised within the RSP.

To define possible retrofitting solutions, 9 different insulation materials were chosen, which can be varied in thickness from 0 to $60 \mathrm{~cm}$ in steps of $1 \mathrm{~cm}$ in combination with 7 different heating systems. For simplicity, it was assumed that all building components that comprise the thermal envelope, e.g. basement ceiling, outer walls, roof, and uppermost ceiling are insulated with the same material and in the same thickness. Additionally, exchanging the windows was considered as an option. The original windows could be exchanged for either double- or triple-glazed windows in a PVC frame. The physical and environmental data employed is shown in Table 3. The embodied impact of the heating system is not considered. Furthermore, coolant leakage from the heat pump and a decrease in performance are also neglected.

This results in a solution space of $9 \times 61 \times 7 \times 3=11529$ possible solutions. Looping through all the possible solutions takes about 20 min on a standard PC, and the solutions are then exported to a spreadsheet and sorted according to the minimum impact for each heating system and each indicator. The results are shown in Figure 9. For the computer-based optimization, a plugin for Grasshopper3D called GOAT (Floery 2015) was used. The evolutionary algorithm CRS2 (Kaelo \& Ali 2006) which is provided by the NLopt library (Johnson 2010) was employed. The optimizer randomly varies the adjustable parameters within the given boundaries to find a first generation of possible solutions. These are evaluated according to the objective function. The best solutions are recombined and form a second generation of possible solutions, which is then re-evaluated. This iterative process is continued until an abort criterion is reached. In this case, it was set to a maximum run time of 6 minutes. To 
verify that the optimizer finds the optimum within the given time limit, an initial simulation was run and compared to the loop of all solutions. The optimizer found the minimum within the given time limit.

At this point, the optimizer was applied for an extended study. Additionally, each of the four building components can be insulated with a different thickness. For a given heating system - a heat pump fuelled by electricity from the German energy mix and a PF of 4.8 (HP $4.8 \mathrm{mix}$ ) - this results in a search space of $9 \times 61^{4} \times 3=373.8$ million possible solutions. For this extended search space, the time limit for the optimizer was set to 15 minutes. The results for minimum PERNT $_{\mathrm{LC}}$ are displayed in Figure 10. Although the calculation of a single solution takes about $0.1 \mathrm{~s}$, the calculation of all solutions would take 432 days on a standard PC. Verification of the solution found by the optimizer by running a loop of all solutions is therefore impractical. It has therefore been assumed that it finds a nearly optimal solution as indicated by the converging solutions shown in Figure 10.

\subsection{Discussion}

The first example shows the application of the developed method for evaluating geometric variants in the conceptual design stage. Figure 8 indicates a great range of results depending on the individual combination of energy standard, material, and heating system. The lowest PENRT $\mathrm{LC}_{\mathrm{C}}$ of $87242 \mathrm{MJ} / \mathrm{a}$ is achieved by geometry 3 with Passivhaus standard, wood construction, and HP4.8. The highest PENRT $\mathrm{LC}_{\mathrm{L}}$ of $328608 \mathrm{MJ} / \mathrm{a}$ results from geometry 4 with EnEV standard, lime sand brick construction, and a gas-condensing boiler. Geometry 4 achieves $133791 \mathrm{MJ} / \mathrm{a}$ using the same combination as the best solution of geometry 3 . The difference of $46549 \mathrm{MJ} / \mathrm{a}$ between the geometric variants corresponds to an increase of $53 \%$ and shows the strong influence of the geometry. It is obvious that a compact building results in a lower environmental impact than six detached houses. In contrast, it was not anticipated that the results of geometry 2 would be better than those of geometry 1 . In general, the notional geometric variants were chosen to exemplify the approach and do not necessarily represent realistic design variants.

The mean value of the results of possible solutions in the next steps represents one way to display the performance of a geometric variant. Other ways, such as the median, or ranges with minimum and maximum values, are possible too. Benchmarks from building certification could also be integrated. Further studies to investigate the most comprehensible way of displaying the results are necessary.

The results of the second example (see Figure 9) show a great variability in optimum insulation thickness depending on the heating system and insulation material. Without entering into a detailed discussion of all the indicators, the results clearly show the importance of considering boundary conditions such as the heating system.

The results also show a great divergence among the different indicators. According to ISO family 14000, eight indicators were evaluated in parallel. However, making a decision on which insulation material and thickness should be employed based on these results is difficult. This shows that the demand for a single score indicator that facilitates communication of the results to the architect or the clients.

In previous studies using the same reference building for retrofitting, EnergyPlus was employed to simulate the energy demand (Hollberg \& Ruth 2014; Klüber et al. 2014). The optimization process took about 3 hours, because each run of the simulation took 10 seconds. The new approach finds the minimum environmental impact 
in the first case within a time frame of 4 minutes, which demonstrates the great advantage of the quasi-steady state approach based on DIN V 18599. EnergyPlus building simulation may still be necessary for office buildings with more complex building services, or for determining cooling demand in other climate zones, but for the calculation of environmental impact for residential buildings in Central Europe, the quasi-steady state approach is sufficient. In future, whether other optimization algorithms are more time-efficient will be investigated.

Numerous assumptions were made in order to reduce the amount of input data, simplify the process, and provide the results in real time. The chosen system boundaries conform to the certification systems DGNB (DGNB 2015) and BNB (BBSR 2015). Nevertheless, the significance of the neglected modules A4, A5, C1 and C2 should be investigated in the future. We neglected the embodied impact of interior outfitting and building services. Assuming that they will not differ much between the different design variants, the ranking of the variants will not change. This is also true for the neglected operational impact from water use, lighting, and appliances. They can become relevant in some cases, e.g. when the significance of an individual retrofit measure is quantified in relation to the LCA of the complete building. In those cases, these aspects can be integrated into the parametric model in the future.

\section{Conclusion}

Many challenges for the application of LCA during the design process can be identified, including a lack in environmental data, a lack in LCA knowledge on the part of designers, and a lack in adequate LCA tools to optimize building designs. We assumed that data availability for building materials will improve and present a parametric method to allow non-LCA-experts to efficiently optimize a design. With the help of this method, the architect receives real-time feedback on the LCA results while designing the building. By incorporating a simplified LCA into the design process, the additional effort of performing LCA is minimized and allows the architect to focus on the main task of designing the building. Two examples of application prove the generation and comparison of design variants to be an effective form of optimization, either undertaken manually by the architect or automatically by an optimizer.

The first example uses the parametric approach to evaluate geometric variants in the conceptual design stage. The information needed for an LCA is usually not available at this stage. Therefore, assumptions for the energy standard, the material, and the heating system are based on typical solutions. With the help of the parametric LCA approach, the possible combinations are calculated for each geometry. The results are an estimation of the environmental impact of each variant when assessed at the end of the design stage. The parametric approach enables the application of LCA to be shifted from design stage 4 to stage 2 , and therefore provides a solution for the dilemma described in the introduction. Based on assumptions for missing information, it is now possible to indicate the potential of a geometric solution in the early design stages.

The second example shows the application of the parametric approach with optimizers for the retrofitting of a single-family house in the detailed design stage. The task was to find the optimum insulation thickness under specific boundary conditions. Even without changing the geometry of the building, i.e. only combining different options for the insulation material, heating systems, and windows, millions of possible solution arise. The results indicate that there is no single optimum insulation thickness, but many optima, depending on the individual boundary conditions and the chosen indicator. It is crucial to integrate these boundaries. In order to communicate 
the results, the choice of indicator becomes very important. For architects with only general knowledge of LCA, a single score indicator would be easier to understand. Once this indicator can be agreed on, it will be integrated in the parametric approach described here to facilitate the communication of results.

Further analyses can be integrated in future. For example, daylight simulation modules can be applied to analyse daylight availability within the building in order to determine the additional artificial lighting needed and the resulting $\mathrm{I}_{\mathrm{O}}$.

In the future, the integration of Life Cycle Costing (LCC) will be investigated. Once a common ground for the evaluation of social aspects within the life cycle has been developed, the parametric method could also be extended for Life Cycle Sustainability Assessment (LCSA).

\section{Acknowledgements}

This study was carried out as part of the research project FOGEB, funded by the Thuringian Ministry for Economics, Labour and Technology and the European Social Funds (ESF) and the project 'Integrated Life Cycle Optimization', funded by the German Federal Ministry for the Environment, Nature Conservation, Building and Nuclear Safety through the research initiative ZukunftBau.

\section{References}

Antón, L.Á. \& Díaz, J., 2014. Integration of LCA and BIM for Sustainable Construction. Int. J. Soc. Manag. Econ. Bus. Eng. 8 (2014) 1345-1349.

Aurélio, M., Benetto, E. \& Koster, D., 2011. Environmental life cycle assessment and optimization of buildings. In LCM 2011.

Baitz, M. et al., 2012. LCA's theory and practice: like ebony and ivory living in perfect harmony? Int. J. Life Cycle Assess, $18(1)$, pp.5-13.

Basbagill, J. et al., 2013. Application of life-cycle assessment to early stage building design for reduced embodied environmental impacts. Build. Environ, 60, pp.81-92.

Bates, R. et al., 2013. Quantifying the Embodied Environmental Impact of Building Materials During Design: A Building Information Modeling Based Methodology. In PLEA. Munich, pp. 1-6.

BauO Bln, 2011. Landesbauordnung Berlin, Germany. Available at: http://www.stadtentwicklung.berlin.de/service/gesetzestexte/de/download/bauen/BauOBln.pdf [Accessed August 8, 2015].

BBSR, 2015. BNB system. Available at: https://www.bnb-nachhaltigesbauen.de/bewertungssystem/bnbbewertungsmethodik.html [Accessed April 4, 2015].

BBSR, 2014. eLCA. Available at: www.bauteileditor.de [Accessed August 8, 2015].

BBSR, 2013. Erläuterungen zur BBSR-Tabelle "Nutzungsdauern von Bauteilen zur Lebenszyklusanalyse nach BNB ." Available at: http://www.nachhaltigesbauen.de/baustoff-und-gebaeudedaten/nutzungsdauern-von-bauteilen.html.

BMVBS, 2013. ökobau.dat. Available at: http://www.nachhaltigesbauen.de/baustoff-und-gebaeudedaten/oekobaudat.html [Accessed August 8, 2015].

CEN, 2012. DIN EN 15978: Nachhaltigkeit von Bauwerken - Bewertung der umweltbezogenen Qualität von Gebäuden. , pp.1-62.

Collinge, W.O. et al., 2013. Dynamic life cycle assessment: framework and application to an institutional building. Int. J. Life Cycle Assess, 18(3), pp.538-552.. 
Davis, D., 2013. Modelled on Software Engineering : Flexible Parametric Models in the Practice of Architecture. RMIT University. Available at: http://www.danieldavis.com/papers/danieldavis_thesis.pdf.

DENA et al., 2012. Der dena-Gebäudereport 2012. Statistiken und Analysen zur Energieeffizienz im Gebäudebestand.

DGNB, 2015. DGNB system. Available at: http://www.dgnb-system.de/en/ [Accessed April 4, 2015].

DIN, 2011. DIN V 18599-2 Energetische Bewertung von Gebäuden - Berechnung des Nutz-, End- und Primärenergiebedarfs für Heizung, Kühlung, Lüftung, Trinkwasser und Beleuchtung - Teil 2: Nutzenergiebedarf für Heizen und Kühlen von Gebäudezonen., p.111.

DOE, 2015. EnergyPlus V8.3. U.S. Department of Energy. Available at: http://apps1.eere.energy.gov/buildings/energyplus/ [Accessed April 4, 2015].

Ekkerlein, C., 2004. Ökologische Bilanzierung von Gebäuden in frühen Planungsphasen auf Basis der Produktmodellierung. Technische Universität München.

EnEV, 2013. Energieeinsparverordnung - Nichtamtliche Lesefassung zur Zweiten Verordnung zur Änderung der Energieeinsparverordnung vom 18. November 2013. , pp.1-90.

EU, 2010. DIRECTIVE 2010/31/EU on the energy performance of buildings, Available at: http://eur-lex.europa.eu/legalcontent/EN/TXT/PDF/?uri=CELEX:32010L0031\&from=EN [Accessed August 2, 2015].

Flager, F. et al., 2011. Multi-objective building envelope optimization for life-cycle cost and global warming potential, in: eWork Ebus. Archit. Eng. Constr., CRC Press, 2012: pp. 193-200.

Floery, S., 2015. Goat. Available at: http://www.rechenraum.com/en/goat/overview.html [Accessed March 3, 2015].

Frenzel, C. \& Hiller, M., 2014. TRNSYSLIZARD - Open Source Tool Für Rhinocerus - Grasshopper. In Fifth GermanAustrian IBPSA Conference. pp. 490-496.

Fuchs, M. et al., 2013. SNAP Systematik für Nachhaltigkeitsanforderungen in Planungswettbewerben - Endbericht, Berlin.

Grasshopper, 2015. Grasshopper3D. Available at: http://www.grasshopper3d.com/ [Accessed August 8, 2015].

Heeren, N. et al., 2015. Environmental Impact of Buildings-What Matters? Environmental Science \& Technology, 49(16), pp.9832-9841. Available at: http://pubs.acs.org/doi/abs/10.1021/acs.est.5b01735.

Hegger, M. et al., 2007. Energie Atlas: Nachhaltige Architektur, Birkhäuser.

Hildebrand, L., 2014. Strategic investment of embodied energy during the architectural planning process. ISBN 9461863268

Hollberg, A. et al., 2016. Application of a parametric real-time LCA tool in students' design projects. In Sustainable Built Environment. Hamburg.

Hollberg, A. \& Ruth, J., 2014. A Parametric Life Cycle Assessment Model for Facade Optimization. In Building Simulation and Optimization. London.

Jakubiec, J.A. \& Reinhart, C.F., 2011. Diva 2.0: Integrating daylight and thermal simulations using Rhinoceros 3D, Daysim and EnergyPlus. In Proceedings of IBPSA. Sydney, Australia.

Johnson, S.G., 2010. The NLopt nonlinear-optimization package. Available at: http://ab-initio.mit.edu/nlopt [Accessed March 3, 2015].

Kaelo, P. \& Ali, M.M., 2006. Some variants of the controlled random search algorithm for global optimization. Journal of Optimization Theory and Applications, 130(2), pp.253-264.

Kellenberger, D. \& Althaus, H.-J., 2009. Relevance of simplifications in LCA of building components. Build. Environ, 44(4), pp.818-825.

El Khouli, S., John, V. \& Zeumer, M., 2014. Nachhaltig Konstruieren Detail Green, Institut für Internationale ArchitekturDokumentation.

Klüber, N., Hollberg, A. \& Ruth, J., 2014. Life cycle optimized application of renewable raw materials for retrofitting measures. In World Sustainable Building. Barcelona.

Lasvaux, S. \& Gantner, J., 2013. Towards a new generation of building LCA tools adapted to the building design process and to the user needs? In Sustainable Building. Graz, pp. 406-417.

Lasvaux, S., Gantner, J. \& Saunders, T., 2012. Requirements for building LCA tool developers, Available at: http://www.eebguide.eu/eebblog/wp-content/uploads/2012/12/D-4.3.-Requirements-for-Building-LCA-tooldesigner.pdf [Accessed August 8, 2015]. 
Lichtenheld, T., Hollberg, A. \& Klüber, N., 2015. Echtzeitenergieanalyse für den parametrischen Gebäudeentwurf. In Bauphysiktage Kaiserslautern. Kaiserslautern: Technische Universität Kaiserslautern.

Lützkendorf, T. et al., 2015. Net-zero buildings: incorporating embodied impacts, Build. Res. Inf., 43(1), pp.62-81.

McLeod, R., Mead, K. \& Standen, M., 2015. Passivhaus primer: Designer's guide, Available at: http://www.passivhaus.org.uk/filelibrary/Primers/KN4430_Passivhaus_Designers_Guide_WEB.pdf [Accessed August $8,2015]$

Nembrini, J., Samberger, S. \& Labelle, G., 2014. Parametric scripting for early design performance simulation. Energy Build, 68(PART C), pp.786-798.

Neuberg, F., 2004. Ein Softwarekonzept zur Internet-basierten Simulation des Ressourcenbedarfs von Bauwerken. Technische Universität München.

Ostermeyer, Y., Wallbaum, H. \& Reuter, F., 2013. Multidimensional Pareto optimization as an approach for site-specific building refurbishment solutions applicable for life cycle sustainability assessment. Int. J. Life Cycle Assess, 18(9), pp.1762-1779.

Passer, A. et al., 2015. Environmental product declarations entering the building sector: critical reflections based on 5 to 10 years experience in different European countries. Int. J. Life Cycle Assess, 20(9), pp.1199-1212.

Passer, A., Kreiner, H. \& Maydl, P., 2012. Assessment of the environmental performance of buildings: A critical evaluation of the influence of technical building equipment on residential buildings. Int. J. Life Cycle Assess, 17(9), pp.11161130 .

Rittel, H.W. \& Reuter, W.D., 1992. Planen, Entwerfen, Design.

Robert McNeel \& Associates, 2015. Rhinoceros3D. Available at: https://www.rhino3d.com/ [Accessed August 8, 2015].

Roudsari, M.S., Smith, A. \& Gill, G., 2013. Ladybug: A parametric Environmental Plugin for Grasshopper to held designers environmentally conscious design. In Building Simulation (IBPSA). Chambéry, France, p. 8.

Seo, S., Tucker, S. \& Newton, P., 2007. Automated Material Selection and Environmental Assessment in the Context of 3D Building Modelling. J. Green Build, 2(2), pp.51-61.

Szalay, A. \& Zöld, Z., 2007. What is missing from the concept of the new European Building Directive? Build. Environ, 42, pp.1761-1769.

Szalay, Z. et al., 2014. Life Cycle Based Optimization of Building Design. In World Sustainable Building. Barcelona, pp. $17-23$.

TRNSYS, 2015. TRNSYS. Thermal Energy System Specialists, LLC. Available at: http://www.trnsys.com/ [Accessed April 4, 2015].

UNEP SBCI, 2009. Buildings and Climate Change Summary for Decision-Makers,

Weißenberger, M., Jensch, W. \& Lang, W., 2014. The convergence of life cycle assessment and nearly zero-energy buildings : The case of Germany. Energy Build, 76, pp.551-557.

Wittstock, B. et al., 2012. EeBGuide Guidance Document Part B: BUILDINGS, Available at: http://www.eebguide.eu/eebblog/wp-content/uploads/2012/10/EeBGuide-B-FINAL-PR_2012-1029.pdflnpapers2://publication/uuid/08A1A363-8E01-4CBB-B710-4ADBDFB14EBB.

Wittstock, B. et al., 2009. Gebäude aus Lebenszyklusperspektive - Ökobilanzen im Bauwesen. Bauphysik, 31.

Zabalza Bribián, I., Aranda Usón, A. \& Scarpellini, S., 2009. Life cycle assessment in buildings: State-of-the-art and simplified LCA methodology as a complement for building certification. Build. Environ, 44(12), pp.2510-2520. 
Tables

Table 1 Present computer-aided LCA tools

\begin{tabular}{|c|c|c|c|c|c|c|c|c|}
\hline Type & Name & $\begin{array}{l}\bar{\Phi} \\
\frac{0}{0} \\
\text { E } \\
\text { ल }\end{array}$ & 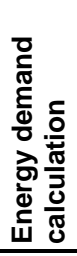 & 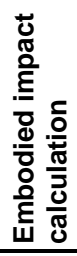 & 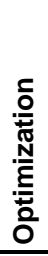 & 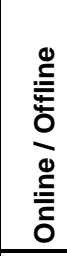 & Country & Website \\
\hline \multirow{4}{*}{ 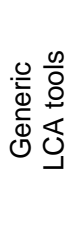 } & Gabi & & & & & Off & Germany & www.gabi-software.com/software/ \\
\hline & SimaPro & & & & & Off & Netherlands & www.pre-sustainability.com/simapro \\
\hline & OpenLCA & & & & & Off & Germany & www.openlca.org/ \\
\hline & Umberto & & & & & Off & Germany & www.umberto.de/en/ \\
\hline \multirow{8}{*}{ 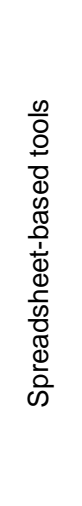 } & Envest $2^{*}$ & & & & O & On & UK & www.envest2.bre.co.uk/index.jsp \\
\hline & $\begin{array}{l}\text { SBS Building } \\
\text { Sustainability }\end{array}$ & & & & & On & Germany & www.sbs-onlinetool.com \\
\hline & Ökobilanz Bau & & O & & & On & Germany & www.oekobilanz-bau.de/oekobilanz/ \\
\hline & eTOOL & & & & & On & Australia & www.etoolglobal.com/about-etoollcd/ \\
\hline & $\begin{array}{l}\text { Athena Impact } \\
\text { Estimator }\end{array}$ & & & & & Off & Canada & $\begin{array}{l}\text { www.athenasmi.org/our-software- } \\
\text { data/overview/ }\end{array}$ \\
\hline & Legep & & & & $\mathrm{O}$ & Off & Germany & www.legep.de/ \\
\hline & Elodie & & & & & Off & France & www.elodie-cstb.fr/ \\
\hline & GreenCalc+ & & & & & Off & Netherlands & www.greencalc.com/index.html \\
\hline \multirow{4}{*}{ 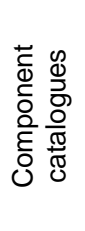 } & EcoSoft & & & & & On & Austria & www.ibo.at/en/ecosoft.htm \\
\hline & Bauteilkatalog & & & & & On & Switzerland & www.bauteilkatalog.ch/ch/de/Bauteilkatalog.asp \\
\hline & eLCA & & & & & On & Germany & www.bauteileditor.de/ \\
\hline & BEES & & & & & On & US & www.nist.gov/el/economics/BEESSoftware.cfm \\
\hline \multirow{5}{*}{ 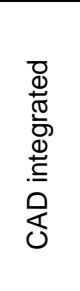 } & Impact & & & & & On & UK & www.impactwba.com/index.jsp \\
\hline & Cocon-BIM & O & & & & Off & France & www.eosphere.fr/ \\
\hline & Lesoai & $\mathrm{O}$ & & & & Off & Switzerland & www.lesosai.com/de/index.cfm \\
\hline & 360optimi & 0 & & & & Off & Finland & www.360optimi.com/en/home \\
\hline & Tally & 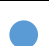 & & & & Off & US & www.choosetally.com/ \\
\hline
\end{tabular}

Partial functionality / additional software needed / external calculation

Full functionality

No new licenses sold, now integrated in Impact 
Table 2 Material variants

1

2

\begin{tabular}{|c|c|c|c|c|c|c|c|c|c|}
\hline & \multicolumn{3}{|c|}{ Wood } & \multicolumn{3}{|c|}{ Lime sand brick (LSB) } & \multicolumn{3}{|c|}{ Concrete } \\
\hline & Material & $\begin{array}{l}\text { Thickness } \\
{[\mathrm{cm}]^{\star}}\end{array}$ & $\mathbf{U}^{*}$ & Material & $\begin{array}{l}\text { Thickness } \\
{[\mathrm{cm}]^{\star}}\end{array}$ & $\mathbf{U}^{*}$ & Material & $\begin{array}{l}\text { Thickness } \\
{[\mathrm{cm}]^{\star}}\end{array}$ & $\mathbf{U}^{*}$ \\
\hline \multirow{4}{*}{ 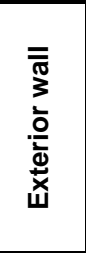 } & $\begin{array}{l}\text { Larch } \\
\text { cladding }\end{array}$ & 2.5 & \multirow{4}{*}{$\begin{array}{c}0.27 \\
/ \\
0.15\end{array}$} & Syn. Plaster & 1.0 & \multirow{4}{*}{$\begin{array}{c}0.26 \\
/ \\
0.15\end{array}$} & $\begin{array}{l}\text { Fibre cement } \\
\text { panel }\end{array}$ & 1.0 & \multirow{4}{*}{$\begin{array}{c}0.28 \\
/ \\
0.15\end{array}$} \\
\hline & WFIB & $14.0 / 26.0$ & & EPS & $12.0 / 22.0$ & & Rockwool & $13.0 / 25.0$ & \\
\hline & Timber frame & 18.0 & & LSB & 18.0 & & $\begin{array}{l}\text { Reinforced } \\
\text { concrete }\end{array}$ & 18.0 & \\
\hline & Plasterboard & 2.0 & & $\begin{array}{l}\text { Gypsum Lime } \\
\text { Plaster }\end{array}$ & 1.0 & & $\begin{array}{l}\text { Gypsum Lime } \\
\text { Plaster }\end{array}$ & 1.0 & \\
\hline \multirow{4}{*}{ ডั̊ } & $\begin{array}{l}\text { Bitumen } \\
\text { sealing }\end{array}$ & 0.5 & \multirow{4}{*}{$\begin{array}{c}0.20 \\
/ \\
0.15\end{array}$} & $\begin{array}{l}\text { Bitumen } \\
\text { sealing }\end{array}$ & 0.5 & \multirow{4}{*}{$\begin{array}{c}0.20 \\
/ \\
0.15\end{array}$} & $\begin{array}{l}\text { Bitumen } \\
\text { sealing }\end{array}$ & 0.5 & \multirow{4}{*}{$\begin{array}{c}0.20 \\
/ \\
0.15\end{array}$} \\
\hline & WFIB & $20.0 / 26.0$ & & XPS & $16.0 / 22.0$ & & XPS & $16.0 / 22.0$ & \\
\hline & Timber frame & 20.0 & & Concrete & 18.0 & & Concrete & 18.0 & \\
\hline & Plasterboard & 2.0 & & Plasterboard & 2.0 & & Plasterboard & 2.0 & \\
\hline \multirow{2}{*}{ 흠 } & $\begin{array}{l}\text { Reinforced } \\
\text { concrete }\end{array}$ & 20.0 & \multirow{2}{*}{$\begin{array}{c}0.32 \\
/ \\
0.15\end{array}$} & $\begin{array}{l}\text { Reinforced } \\
\text { concrete }\end{array}$ & 20.0 & \multirow{2}{*}{$\begin{array}{c}0.32 \\
/ \\
0.15\end{array}$} & $\begin{array}{l}\text { Reinforced } \\
\text { concrete }\end{array}$ & 20.0 & \multirow{2}{*}{$\begin{array}{c}0.32 \\
/ \\
0.15\end{array}$} \\
\hline & XPS & $10.0 / 22.0$ & & XPS & $10.0 / 22.0$ & & XPS & $10.0 / 22.0$ & \\
\hline \multirow{2}{*}{ 옴 } & OSB & 3.8 & & \multirow{2}{*}{ Concrete } & \multirow{2}{*}{18.0} & & \multirow{2}{*}{ Concrete } & \multirow{2}{*}{18.0} & \\
\hline & Timber frame & 18.0 & & & & & & & \\
\hline \multirow{4}{*}{ 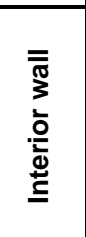 } & Plasterboard & 2.0 & & $\begin{array}{l}\text { Gypsum Lime } \\
\text { Plaster }\end{array}$ & 1.0 & & $\begin{array}{l}\text { Gypsum Lime } \\
\text { Plaster }\end{array}$ & 1.0 & \\
\hline & WFIB & 6.0 & & LSB & 14.0 & & Concrete & 14.0 & \\
\hline & Timber frame & 14.0 & & $\begin{array}{l}\text { Gypsum Lime } \\
\text { Plaster }\end{array}$ & 1.0 & & $\begin{array}{l}\text { Gypsum Lime } \\
\text { Plaster }\end{array}$ & 1.0 & \\
\hline & Plasterboard & 2.0 & & & & & & & \\
\hline $\begin{array}{c}\text { Wind } \\
\text { ow }\end{array}$ & \multicolumn{2}{|c|}{$\begin{array}{l}\text { Double/Triple glazing } \\
\text { wood frame }\end{array}$} & $\begin{array}{c}1.3 / \\
0.8 \\
\end{array}$ & \multicolumn{2}{|c|}{$\begin{array}{l}\text { Double/Triple glazing } \\
\text { PVC-U frame }\end{array}$} & $\begin{array}{c}1.3 / \\
0.8 \\
\end{array}$ & \multicolumn{2}{|c|}{$\begin{array}{l}\text { Double/Triple glazing } \\
\text { PVC-U frame }\end{array}$} & $\begin{array}{c}1.3 / \\
0.8 \\
\end{array}$ \\
\hline
\end{tabular}

* Energy standard (EnEV / Passivhaus) 
Table 3 Physical and environmental data of materials used

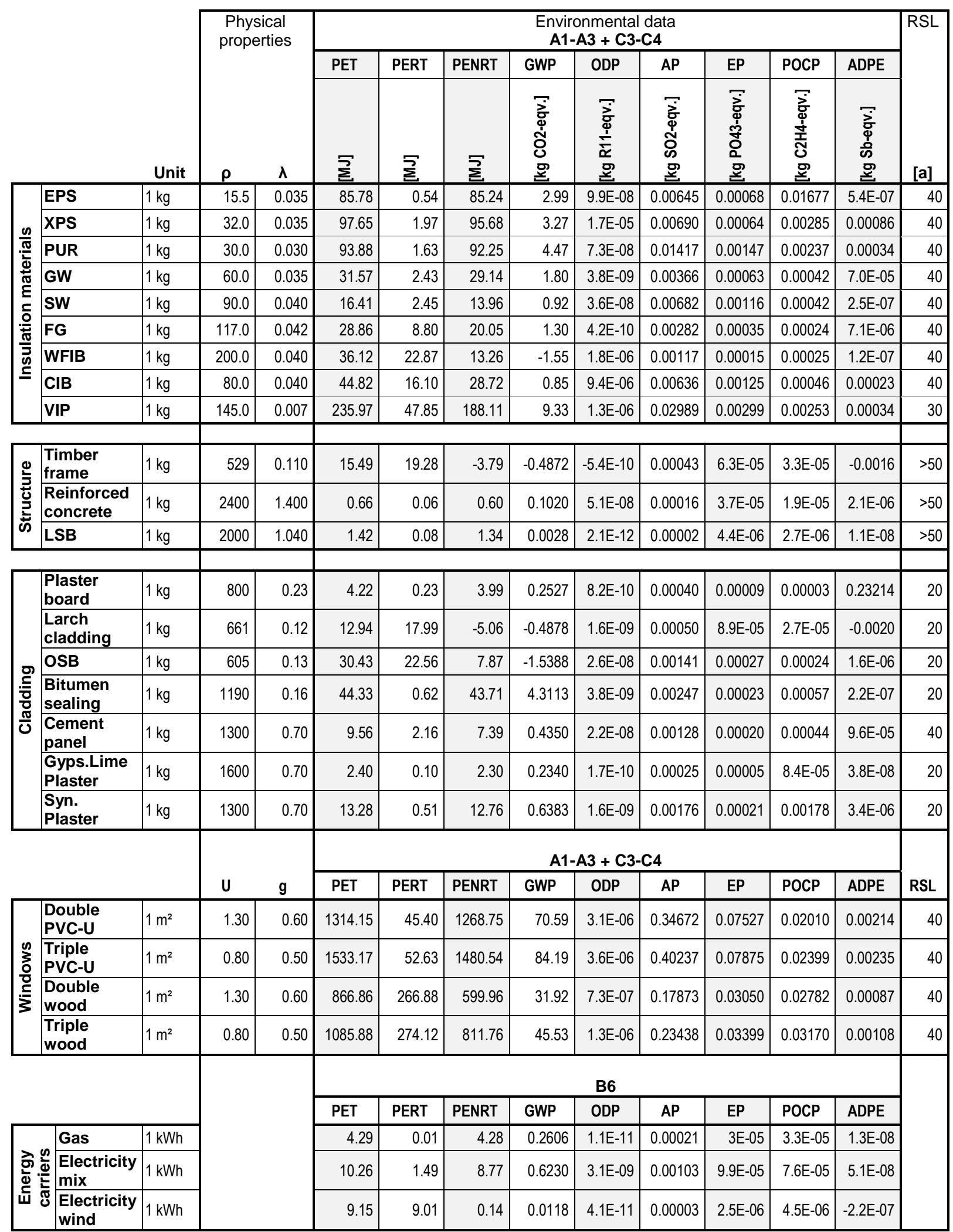

*coolant leakage and decrease in performance are not considered 
Figures

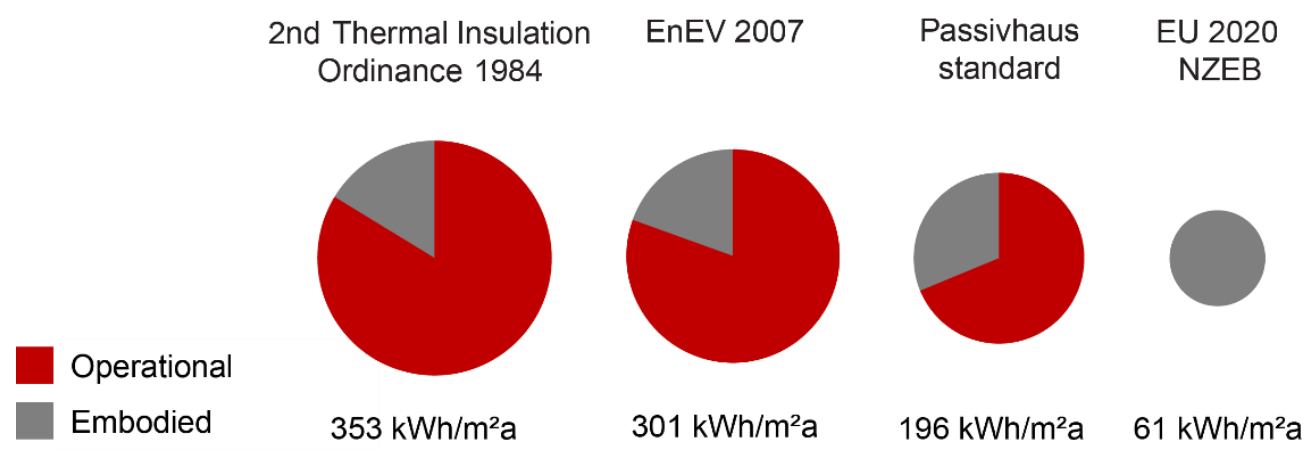

Figure 1 The proportion of operational and embodied energy in the primary energy demand of residential buildings in different German energy standards for a reference service period of 50 years based on Fuchs et al. (2013)

1. Preliminary studies

Feasibility studies, call for competition

2. Concept Design

Concept, sketches, competition design

3. Developed Design

Elaboration of design, building permit

4. Technical Design

Detailed planning, procurement

5. Construction

Construction surveillance

6. Use

Hand over, operation

Costs/Environmental Impact Uncertainty

Figure 2 Six stages in the architectural design process, after Hegger et al. (2007) and El Khouli et al. (2014) 

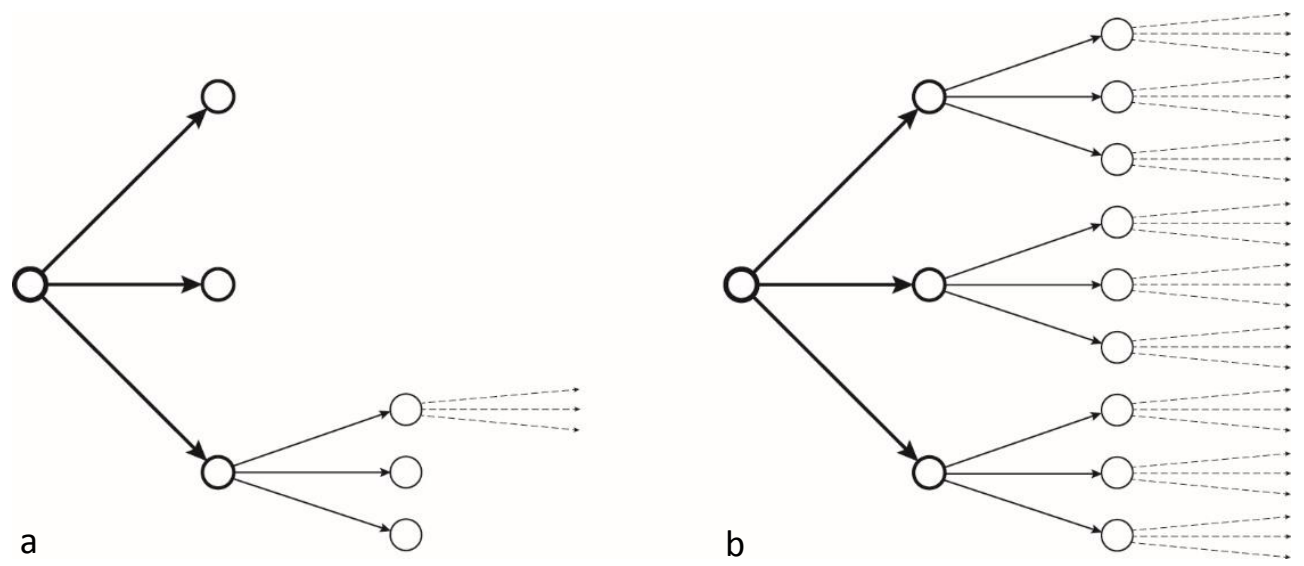

Figure 3 Traditional process with variants (a) and decision tree (b), based on Rittel \& Reuter (1992)

\begin{tabular}{|c|c|c|c|c|c|c|c|c|c|c|c|c|c|c|c|c|}
\hline \multicolumn{3}{|c|}{ Product } & \multicolumn{2}{|c|}{ Construction } & \multicolumn{7}{|c|}{ Use Stage } & \multicolumn{4}{|c|}{ End of Life } & \multirow{2}{*}{$\begin{array}{c}\text { Benefits and loads } \\
\text { beyond the system } \\
\text { boundary }\end{array}$} \\
\hline $\mathrm{A} 1^{*}$ & $\mathrm{~A} 2^{*}$ & $\mathrm{~A} 3^{*}$ & A4 & A5 & B1 & B2 & B3 & $B 4^{*}$ & B5 & $B 6^{*}$ & B7 & C1 & $\mathrm{C} 2$ & $\mathrm{C}^{*}$ & $\mathrm{C} 4^{*}$ & \\
\hline 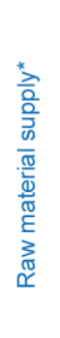 & 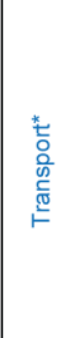 & 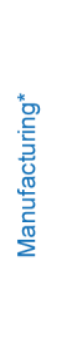 & 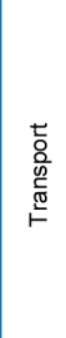 & 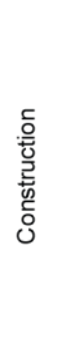 & 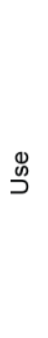 & 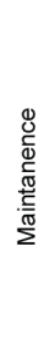 & 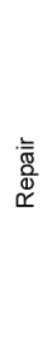 & 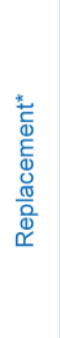 & 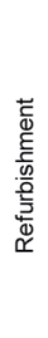 & 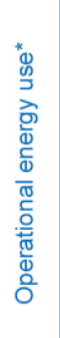 & 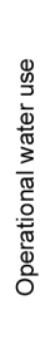 & 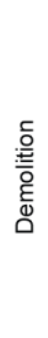 & $\begin{array}{l}\text { t } \\
\frac{0}{0} \\
\frac{0}{0} \\
\frac{\pi}{1} \\
\vdash\end{array}$ & 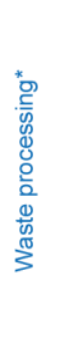 & $\begin{array}{l}\frac{k}{\pi} \\
0 \\
\frac{0}{0} \\
\frac{0}{0}\end{array}$ & 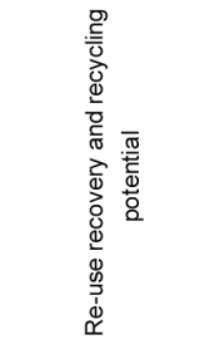 \\
\hline
\end{tabular}

*Life cycle modules that are integrated in the calculation

Figure 4 Life cycle stages considered (CEN/TC 350 2012) 


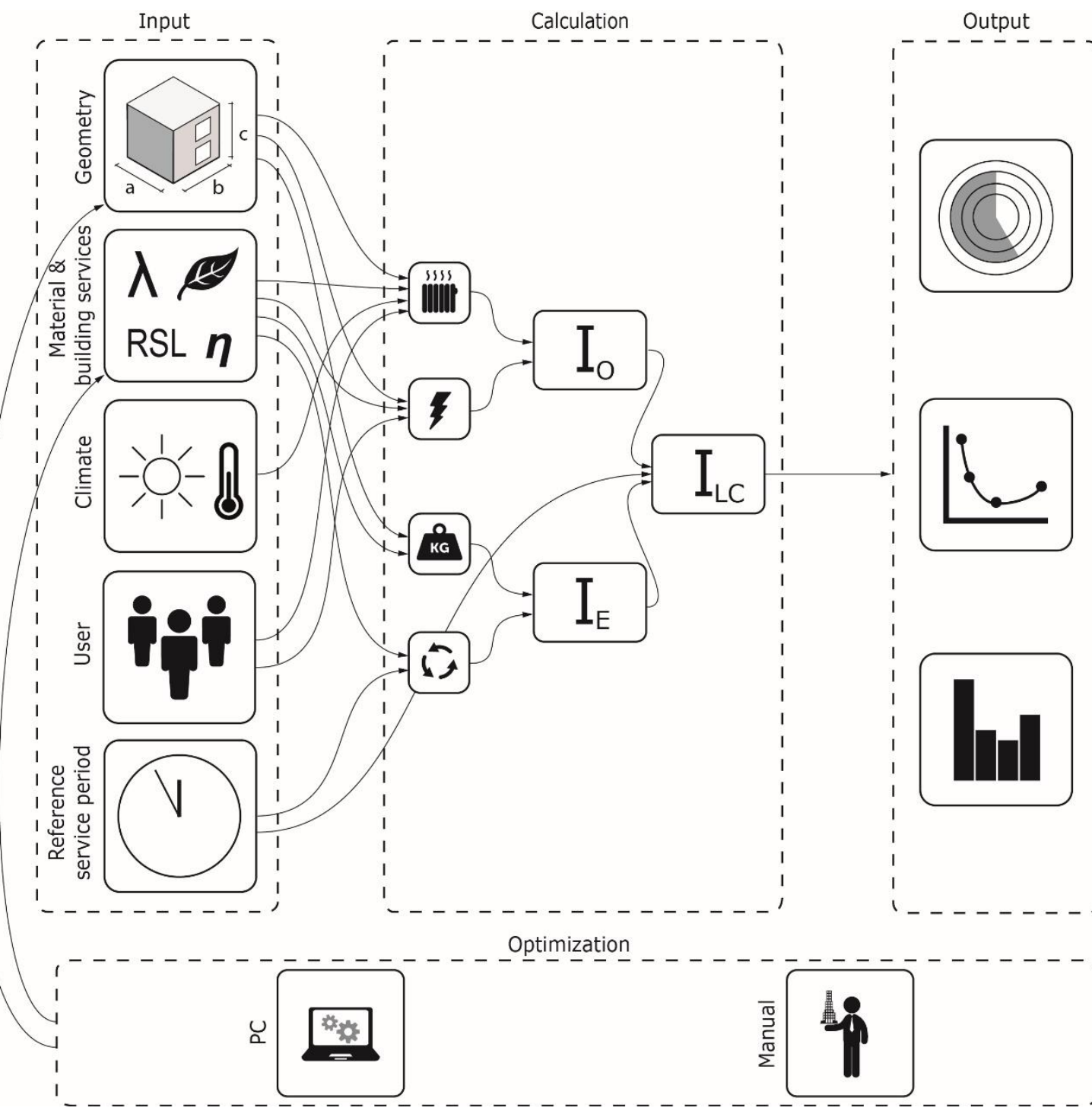

Figure 5 Concept of the parametric workflow 
Building service components

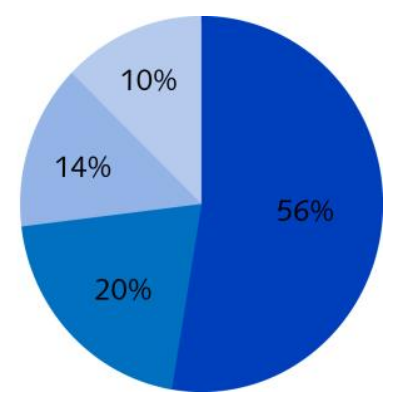

Figure 7 Embodied primary energy for different groups of building components (El Khouli, John, and Zeumer 2014) 


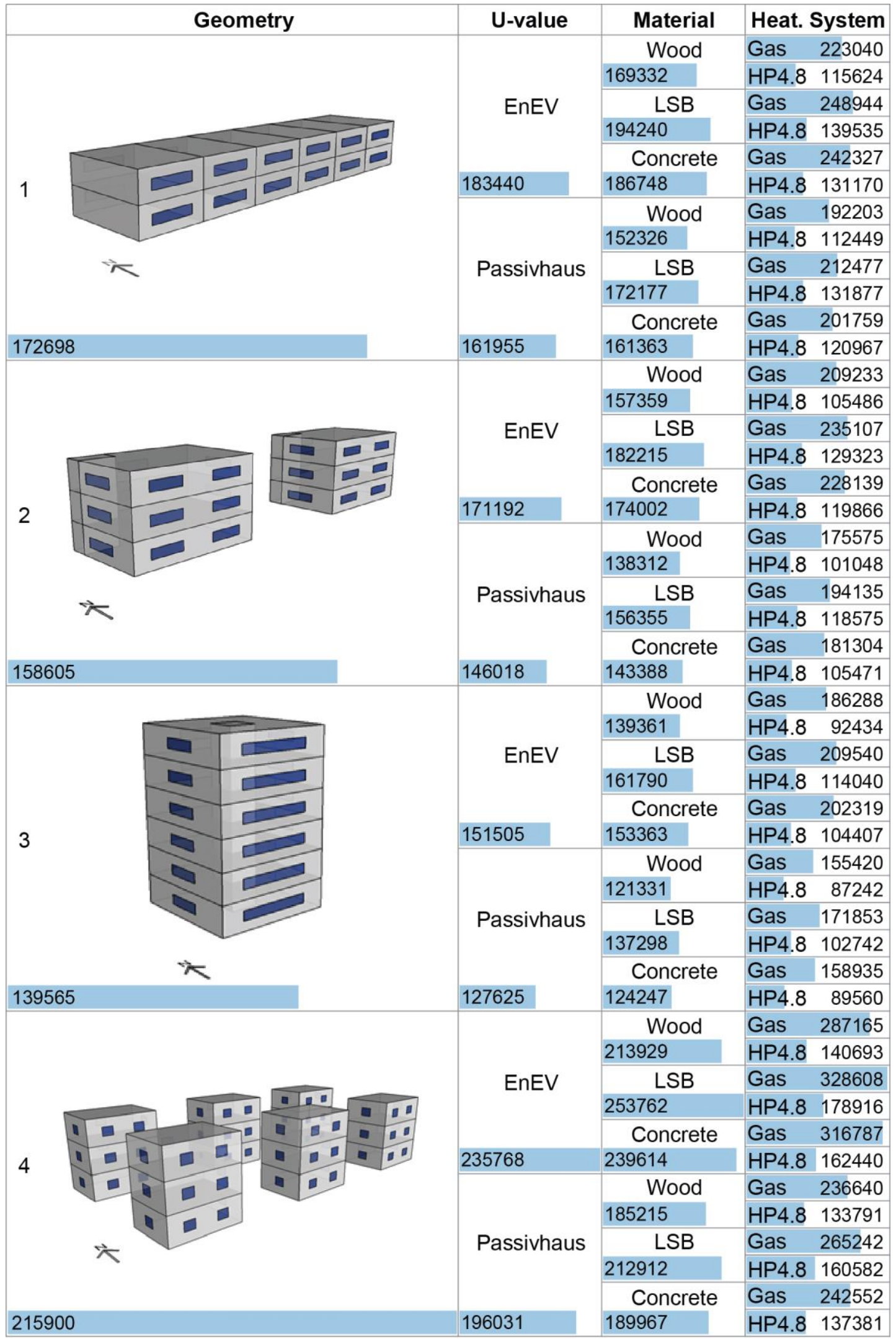

Figure 8 Results for PENRT ${ }_{L C}$ in [MJ/a] 


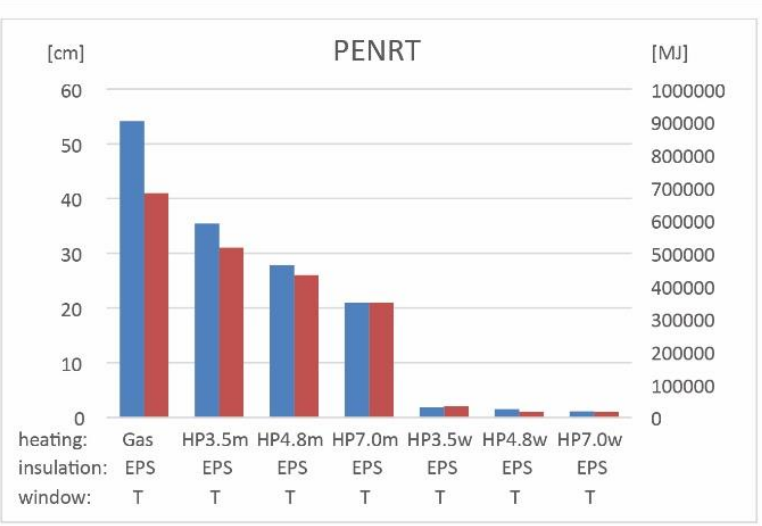

(tan)
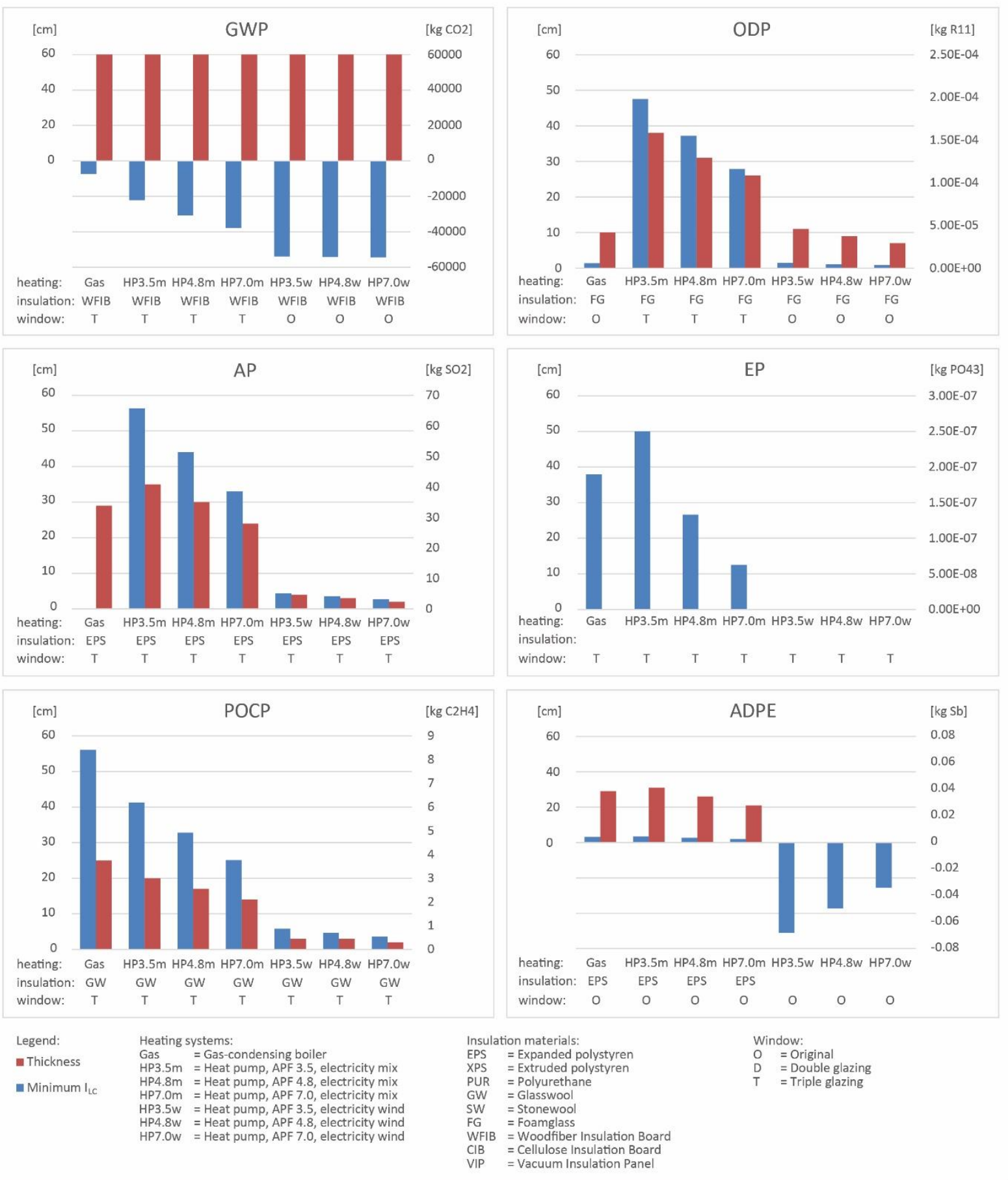

Figure 9 Results for minimum $I_{L C}$ depending on heating system and indicator 
1

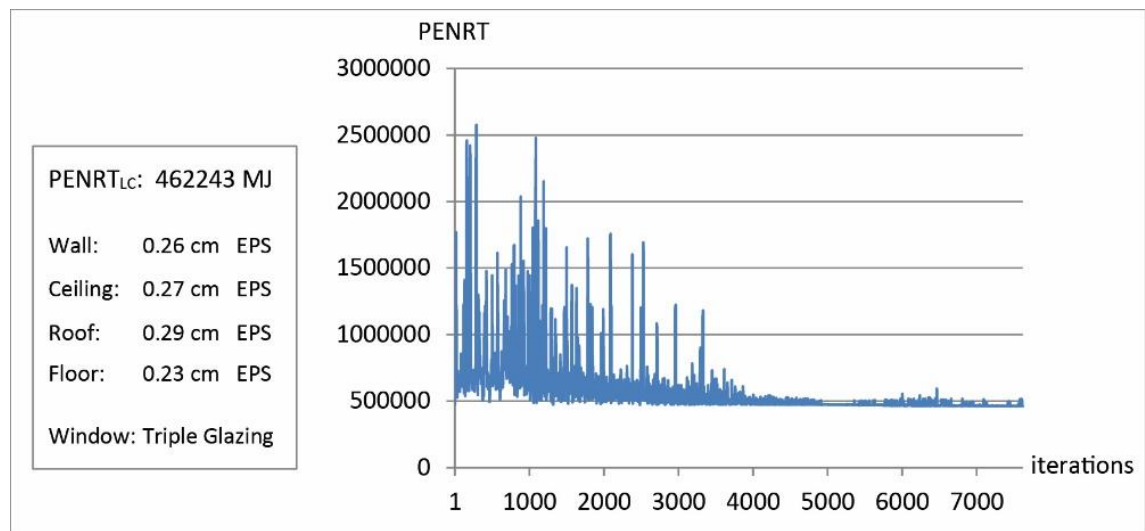

Figure 10 Best combination of insulation material and thickness for PERNT ${ }_{L C}$ and HP 4.8 mix and process of optimization 


\begin{tabular}{|c|c|}
\hline Reviewers comments & Action taken \\
\hline $\begin{array}{l}\text { Abstract: This is a little bit long and loose esp. in the concluding } \\
\text { section. The whole Abstract can be rewritten much tighter from top to } \\
\text { bottom. The Purpose can be distilled with a statement of need, } \\
\text { purpose and value/benefit. Methods should be rewritten to focus on } \\
\text { the research methodology employed to address the purpose. } \\
\text { Conclusion should be about conclusions, and then a bit about } \\
\text { implications to next step(s) of research and to practice. }\end{array}$ & The abstract has been rewritten according to the recommendations \\
\hline $\begin{array}{l}\text { Introduction: On challenges (section 1.3), the foremost challenges are } \\
\text { the lack of data and the lack of LCA expertise by designers. While the } \\
\text { paper does not address the former, this can be justified by a simple } \\
\text { phrase such as "assuming relevant local LCA datasets are available..." } \\
\text { The latter is, of course, addressed by LCA experts incorporating their } \\
\text { knowledge in design tools that allow the designers to focus on their } \\
\text { capability/expertise (like what this paper is about, etc) }\end{array}$ & The proposed points have been added to section 1.3 \\
\hline \multirow{2}{*}{$\begin{array}{l}\text { The notes on, or mention of, "architecture competitions" in the text } \\
\text { and Fig. } 2 \text { should be qualified as special case (normal design projects } \\
\text { do not involve an architecture competition, esp. for the type and size } \\
\text { of building projects as given in the examples in this paper). }\end{array}$} & $\begin{array}{l}\text { The sentence "in the case of an architectural competition...." has been } \\
\text { added. }\end{array}$ \\
\hline & $\begin{array}{l}\text { Figure } 2 \text { has been adapted and mentions the typical tasks in each } \\
\text { stage. }\end{array}$ \\
\hline $\begin{array}{l}\text { Methods: There are two types of 'system boundaries' in buildings: one } \\
\text { pertains to a material/product LCI/LCA and the other relates to the } \\
\text { whole building life cycle as reflected in Figure } 4 \text {. This should be noted } \\
\text { in section } 2.2 \text { and Fig. } 4 \text { should be introduced here. Table } 3 \text { refers to } \\
\text { Fig. } 4 \text {. The paper should be clear in both the text and in Fig. } 4 \text {, that the } \\
\text { current approach only includes stages A1-A3, etc -- for clarity and } \\
\text { transparency. }\end{array}$ & $\begin{array}{l}\text { This point is now mentioned in section } 2.2 \text { with reference to figure } 4 . \\
\text { The life cycle modules integrated in the calculation have been } \\
\text { indicated with a * in Figure } 4 .\end{array}$ \\
\hline $\begin{array}{l}\text { And that while in section } 2.3 .2, \mathrm{Eq}(1) \text { is the general formula, in the } \\
\text { current paper the embodied impact part only covers those } \\
\text { noted/marked in Fig. } 4 .\end{array}$ & $\begin{array}{l}\text { Section } 2.3 .2 \text { now mentionds "While this is a general formula only the } \\
\text { life cycle modules indicated in Figure } 4 \text { are integrated in the } \\
\text { calculation in this paper." }\end{array}$ \\
\hline $\begin{array}{l}\text { Conclusion: Should reflect the adjustments due to all the suggestions } \\
\text { above. }\end{array}$ & The first paragraph of conclusion has been rewritten. \\
\hline $\begin{array}{l}\text { Overall, there may also be some minor English editorial checks and } \\
\text { adjustments (e.g. a stray word that needs to be deleted, adding 'the' } \\
\text { where needed, etc) }\end{array}$ & The paper has been proof-read by a native English speaker \\
\hline
\end{tabular}

Abstract: This is a little bit long and loose esp. in the concluding

section. The whole Abstract can be rewritten much tighter from top to se can beed

the research methodology employed to address the purpose.

ins ren about

Introduction: On challenges (section 1.3), the foremost challenges are

The latter is, of course, addressed by LCA experts incorporating their

The notes on, or mention of, "architecture competitions" in the text

Methods: There are two types of 'system boundaries' in buildings: one pertains to a material/product LCI/LCA and the other relates to the And that while in section 2.3.2, Eq (1) is the general formula, in the noted/marked in Fig. 4. above. 